\title{
Acetogenium kivui gen. nov., sp. nov., a Thermophilic Acetogenic Bacterium
}

\author{
JOHN A. LEIGH AND RALPH S. WOLFE* \\ Department of Microbiology, University of Illinois, Urbana, Illinois 61801
}

\begin{abstract}
We propose that Acetogenium be placed in the family Propionibacteriaceae and provide a formal description of the genus.
\end{abstract}

The isolation and characterization of Acetogenium kivui have been described, and a discussion of the distinguishing characteristics of this organism have been presented (1). A phylogenetic comparison of $A$. kivui and other anaerobic bacteria capable of synthesizing acetate from $\mathrm{CO}_{2}$ has been carried out by using the $16 \mathrm{~S}$ ribosomal ribonucleic acid oligonucleotide cataloging method (2). This study confirmed that $A$. kivui belongs to a new genus, which is distinct from all previously established genera of sporeforming and nonsporeforming acetogens. Members of the genus Acetogenium do not form heatresistant spores and therefore differ from Clostridium thermoaceticum, Clostridium thermosaccharolyticum, and Clostridium thermoautotrophicum $(2,3)$, all of which are thermophilic and can be grouped in a phylogenetic dendogram with A. kivui. Members of this genus differ from other described acetogenic bacteria by their thermophilic nature and lack of motility. Like some species of the genus Eubacterium, A. kivui is not phylogenetically related to all species of Propionibacterium (2). However, for the purpose of classification, we suggest that Acetogenium be placed in the family Propionibacteriaceae.

A formal generic description is given below. Acetogenium (a.ce.to.gen'i.um. L.n. acetum vinegar; Gr.v. suff. genium producing; M.L. neut. n. acetogenium vinegar producing). Obligately anaerobic, thermophilic, nonsporeforming, nonmotile, straight rods which produce principally acetic acid from a variety of substrates, including sugars. Ultrastructure studies show a gram-positive cell wall structure, although $A$. kivui has a negative Gram reaction. Other substrates for growth and acetic acid production may include $\mathrm{H}_{2}$ and $\mathrm{CO}_{2}$, formate, carbon monoxide, and pyruvate. Reducing agents (e.g., cysteine-sulfide) are required. Catalase negative.

The type species is A. kivui. A formal specific description of $A$. kivui has been presented previously (1). The type strain of $A$. kivui is strain ATCC 33488 (= DSM 2030).

\section{LITERATURE CITED}

1. Leigh, J. A., F. Mayer, and R. S. Wolfe. 1981. Acetogenium kivui, a new thermophilic hydrogen oxidizing, acetogenic bacterium. Arch. Microbiol. 129:275-280.

2. Tanner, R. S., E. Stackebrandt, G. E. Fox, R. Gupta, L. J. Magrum, and C. R. Woese. 1982. A phylogenetic analysis of anaerobic eubacteria capable of synthesizing acetate from carbon dioxide. Curr. Microbiol. 7:127-132.

3. Wiegel, J., M. Braun, and G. Gottschalk. 1981. Clostridium thermoautotrophicum species novum, a thermophile producing acetate from molecular hydrogen and carbon dioxide. Curr. Microbiol. 5:255-260. 